\title{
The Utilitarian Decision Making from Islamic Perspectives: Review and Settlement Attempt
}

\author{
Mohammed Al-aaidroos ", Norleyza Jailani*, Muriati Mukhtar" \\ \# * Research Center for Software Technology and Management, Faculty of Information Science and Technology, \\ Universiti Kebangsaan Malaysia, Bangi, Selangor, 43600, Malaysia \\ E-mail:maidroos@gmail.com,njailani@ukm.edu.my,muriati@ukm.edu.my
}

\begin{abstract}
Utilitarian decision making is a far-famed mechanism that alleged to model humans decisions with the help of certain functions known as utility functions. Utilities metaphorically evaluate alternatives and approximate the satisfaction afforded by each. The utilitarian model is considered the fundamental basis of several artificial intelligence techniques such as game theory, evolutionary, heuristic, and fuzzy based approaches. It has been immensely utilized to develop various intelligent systems such as Decision Support Systems (DSS), Negotiation Support Systems (NSS), Multi-Agent Systems (MAS), Shopbots, and proxy bidding systems. Well known that the utilitarian model has been developed based on the hypothesis of rationality and maximization which embodied some secular norms. Islam, on the other hand, has been derived from a diverse set of provisions in which highly upholds tender values and pays significance to moral issues. As a consequence, this paper conducts a brief comparison and deduced two commons bases and four discrepancies. In the time Islam accepts utilitarian conception and do not mind the acquisitive behaves which considered essential in life success but satirically criticizes egoistic encouragement, non-satiation, and un-prioritized preferences. The Islamic objections on the utilitarian decision are not necessarily meant the solid inapplicability but a reasonable treatment out to take place in order to be Islamic legitimated. Introducing the altruistic utility supposedly drops the egoistic objection and then a satiated lexicographic utility hoped to cancel the rest of contradictions. The adoption of those treatments ought to assist in developing intelligent systems that rely on Islamic legitimated decision method which upholds the Islamic moral injunctions. It is hoped that this research will provide the impetus for researchers to propose systems that rely on Islamic legitimate decision making.
\end{abstract}

Keywords - Islamic utility; utilitarian decision making; Islamic utility model

\section{INTRODUCTION}

Utilitarian decision making is a far-famed mechanism that alleged to model human's decisions with the help of certain algebraic functions known as utility functions. The term "utility" was first introduced in 1738 by a Swiss mathematician called Daniel Bernoulli when revealed that money value is judged by human's perceptions more than the real numerical value [1]. Later on, 1944 Von Neumann and Morgenstern attracted by the idea and introduced the basic utility axioms where each utility function must preserve the properties of transitivity, continuity, completeness, and Independency [2]. In order to understand individual's preferences and their decisions making with respect to choices and alternatives, the utilitarian model assumes diverse valuation for each choice in terms of the extent of self-satisfaction that choice produce. Metaphorically, the utility function is considered as equal to the individual's satisfaction where the more satisfactory a choice means more preferred [3]. Therefore, economists and decision theorists usually realize the term utility as the measure to individual welfare and happiness [4].

Computer scientists have found the utilitarian decision model as a great method to simulate the humans' decisionmaking. There are several artificial intelligence (AI) techniques such as game theory, evolutionary, heuristic, and fuzzy approaches which fundamentally rely on the utilitarian decision model [5]. Those approaches have been immensely utilized in developing automated systems such as Decision Support systems (DSS) and negotiation support systems (NSS), multi-agent systems (MAS) [6], [7]. In addition, automated trading systems such as Shopbots, bilateral negotiation, and proxy bidding systems have been vastly utilizing the utilitarian model to fully automate the purchase process [8], [9]. ShopBot, for instance, demonstrated a method to crawl the web aiming to find the best-suited product from multiple vendors [8]. Automated negotiators leverage the autonomous functionality of software agents to engage in one-to-one bilateral negotiation [10]. Proxy bidders continuously inspect auctions to deliberate, assess, and take decisions on behalf of real bidders [9]. The core 
component of these automated trading systems is the dynamic forecasting strategy which mostly implemented using utility-based decision approaches [5].

Nonetheless, the fundamental theory and core concepts behind the utilitarian model have been developed in-line with the secular norms in which decisions are taken with no concern to moral implications [11]. Under the hypothesis of rationally and utility maximization, the decision maker assumed to behave egocentrically in which judged by individual interest and seek to achieve self-pleasure without satiation. The consequent mathematical reflection of these assumptions is the two-deferential concaved algebraic functions such as logarithmic, exponential and power functions where each ultimately maximized with gradual diminishing amount [2].

On the contrary, Islamic resources are filled out with tender feelings such as compassion, kindness, cooperation, altruism, and charity with more emphasis on others wellbeing that ought to start from dependants, family, neighbours and reaching to the whole community, nationals, mankind and other creatures as well. These instructions are supposedly emulated in Muslims behaviour and in particular mainly influence their decisions in a contradiction to selfinterest assumption aforementioned. The merciful behaviour obligates for self-sacrifice where a spiritual satisfaction obtained at expense of a mortal one. This leads to a fluent dimension of moderation where Islam urges in various aspects. Balanced and precise behaves seems Islamic legitimated compared to the un-satiated maximization where bad influences surely persist. Thus, in a broad sense, the utilitarian model encounters a substantive conflict to Islamic principles and seems inadequately interpret Muslims decision making as have been declared by many Muslims economists such as [12]. Consequently, this paper subsists to identify the extent of differences and the probable settlements the model can have in order to be Islamic legitimated. It is hoped that this research will provide the impetus for researchers to propose intelligent systems which originated from Islamic teachings and upholds the Islamic moral injunctions. As a demonstration, our research in [13] has proposed a lenient negotiation decision model that can stimulate sympathy and benevolence in bilateral agentmediated negotiation. Similar automated trading agents hoped to be seen in the near future.

\section{MATERIALS AND METHODS}

Very obvious the vast difference between secularism and Islam and the philosophical attitudes that each pursued. Islam is a monotheistic religion revealed by Allah to his messenger prophet Muhammad -peace be upon him- in which clearly articulated on the Holy Quran. In contrast, secularism can be defined as "the deliverance of man first from religious and them from metaphysical control over his reasons and his language the dispelling of all closed world views, the breaking of all supernatural myths and sacred symbols" [14]. This definition, without a doubt, demonstrates the harm effect of secularism to Muslim's belief in Almighty Allah and the hereafter that Islam upholds. As the word "secular" implies, secularism is a worldly perception toward life, nature, and even human in a sense of salvation from everything spiritual or intangible since there is no evidence of its existence. Accordingly, the differences raised in many fundamental matters related to the wisdom of existence, worldview, and philosophy of life [15].

Muslims believe in the oneness and greatness of God who is only worthy of worship. Allah is the absolute creator of this world and every creature therein and he is the actual owner of the Universe. Human being is the viceroy (Khalifa) and should behave in accordance with God's laws. Muslims, therefore, encouraged discovering, transforming, and consuming the resources endowed in this word to satisfy his needs [16]. Thus, the Islamic doctrine establishes the connection to the true creator and links everything to him as a sign proves his existence. In contrast, secular theologies frankly declared their atheism in which they believe on the non-existence of God and self-existence of the Universe. Influenced by Evolution theory, secular theorist looks to the Universe as pure materialism in which all organism and cosmic components originated through a long process of evolution. At the end this implies directly to the denial of God and therefore -according to them- the man becomes free from supernatural myths [15]. In addition, secularism looks to nature and the surrounding environment as the reservoir of resources in which organisms compete to possess as that essential for their survival. However, resources are limited and a human is inborn with desires and wants which cannot be satisfied unless behaves individualistic. This worldview clearly influences the basic assumptions in which the utilitarian model builds up on and to very high extent contradicts the Islamic doctrine. That is because the greatness of creator implies to his ability to create integrated world with full of resources sufficient for all kinds not only mankind alone as reported in Al-Quran "Allah says How many creatures that carry not their own sustenance? it is God Who feeds (both) them and you" [17]. In fact, the secularism world view originated because of the losing battle of Christianity and the failure to convince the modernized western man.

Knowing the impacts secularism brought to the utility model, a natural question raises whether such model reasonable from Islamic point of view or not and what is the extent of acceptability? However, for comprehensive and equitable decision a detailed investigation for commonalities, differences, and treatments ought to take place. The common denominators and the disparities are discussed below.

\section{A. Common Denominators}

The famous dictum of Islamic jurists which said "The basic principal in all things are permissible unless there is adverse evidence" can be cited here to note that Islamic principles are principally openness and flexible [18]. Accordingly, a deep investigation is required to identify compatible utility principles from those which incompatible or contradicts Sharia provisions. Overall, there is semiconsensus that utilitarian model possession a prominent place in decision making methods especially in microeconomic and artificial intelligence. Taking into account that success thusly urges for identifying the utility acceptable aspects from Islamic perception where there is no conflict with the basic Islamic Sharia. Particularly, there are two aspects seem relevant from Islamic point of view namely the 
utility conception and acquisitive nature in which can be briefly discussed as follows:

1) Utility Relation: Basically, the absolute utility concept in which mathematically approximating human attitude towards some decisions has nothing opposed Sharia principles and can faithfully say that there is no single Islamic evidence (Daleel) found that contradicts it. This leads to the acceptance of the popular utility relation in its compact form in which "an alternative $\mathrm{X}$ considered better than another $\mathrm{Y}$ if and only if its consequence valuation using suitable mathematical utility function is greater than the second alternative". The corresponding symbolic interpretation can be seen in equation (1).

$$
\forall x, y \in A, \quad x<y \quad \text { iff } U(x)<U(y)
$$

This idea can be supported when exploring several published articles in which raised several arguments related to Islamic consumer behaviour theory without declared anything related to the foretasted utility relation. See for instance the studies in [19], and [20]. Moreover, the relation comes in line with Islamic preferred characteristics of initiatives, productivity, and stimulations since it encourages for advancement. Accepting that as a common base will provide a reasonable start toward an Islamic complaint decision model but not necessarily meaning fully accord. That is because there are several complaints raised on the utilized utility function and it is behaviour either embodied the Islamic principles or not.

2) Acquisitive Nature (Pursue Advancement): One of the dialectic principles in the utilitarian model is the utility maximization in which preferences assumed to be ascendant where more always better than less. Despite the argumentation raised on this, basically, Islam confesses that human is violent in liking wealth because that is part of human Instinct and psychology. The evidence of this is the Quranic verse "And lo! in the love of wealth he is violent" (Al-'Adiyat:08) . According to [21] most of the Islamic interpretation of the Arabic word 'Khair' is refereeing to wealth especially the excessive and violent acquisition of wealth. The sober understanding of this text never implies the stimulation impulsive behaves since it will contradict other verses, but to emphasize the need for adjust such behaves without omitting human nature. With this regard, a deduction can be obtained in which both utilitarian and Islam pursues individuals to follow the best for themselves. Consequently, choosing the best suited alternative or the decision with better payoffs i.e. the one with higher utility value has nothing wrong from Islamic point of view.

Yet, the Islamic provisions, however, insist for disciplined attitudes without exaggeration. Accordingly, noticeable distinctions from the conventional utility maximization principle ought to be stated here. Firstly, maximizing selfutility at expense of others is inacceptable in Islam because it opposes tender behaves that Islam usually urges. Secondly, Islam urges for balanced and moderated behaves in which violated when considering the un-satiated maximization property due to predator and violence behave it causes especially with respect to financial imbalances. The detailed distinction is going to be presented in the upcoming sections.

\section{B. Fundamental Disparities}

It is about three decades when Muslim scholars note the dissimilarities between Islamic principles and the utility model in terms of consumption theory and its influences in the purchase decision. Through literature, it seems that Alzarqa discussion in is the first Muslim scholar who recorded objections against the conventional micro-economic tools that tightly depend on the utility model. Since that time several papers tries to discuss this matter and raises more objections from Islamic perception.

In a broad sense, the main reason for these differences is the strong impact of secular norms which leads to some contradictions to Islamic principles especially the core utility hypothesis and axioms. In general, the major disparities can be summarized in four aspects including egoistic behaves, maximization, un-satiated, and continues preferences. In order to fully aborting each of those aspects, the upcoming sections going to investigate each in brief.

1) Egoistic Behaves: The sole justification for a decision maker to induce the uppermost maximum utility is the physiological egoistic feeling [3], [11]. This is an essential building block of the utilitarian model in which usually seen as a fact beyond dispute even though empirically failed. That is because noticeable humans behave in which seen permanently preferring more to less in various aspects. However, so far there is no empirical prove that support this assumption since experimental results such as proves that altruistic behaves also persists. Despite that, the main influence of egoistic behaves is the social confrontation in all life's aspects in which violent competition becomes the source of inspiration. Concentrating on self-desires seems endless and never achieves equilibrium which at the end leads to social expediency collisions. Under such assumption, it is inconceivable to concede part of your wealth to your brother unless there is a visible or invisible benefit such as reputation and goodwill [12]. Clearly now the utilitarian model only capable form interpreting part of human behaves which can be described as predator, rapacious, reckless, impetuous and careless of others even though they are co-partners. Clearly, such behaves inacceptable in Islam and most moral philosophies worldwide.

Islamic philosophy comes in the other direction in which altruism and tender behave plays a significant role in Muslims daily life. Moreover, Al-Quran declared in Surat Al-Syams verse number 7 and 8 that human innate compromising of both wrong and right badness and goodness where the responsibility holds on the Day of Judgment. Obviously, egoism is bad and altruism is good and therefore both behaves must be interpreted with encouragement for good in order to adjust the bad deeds. Within that, the third pillar of Islam is al-Zakah which obliges the payment of certain amount of wealth yearly to needy. Moreover, the most value emphasized in Al-Quran is to give for the sake of Allah i.e. Infaq-fisabillillah because it mentioned 54 times in different places in Al-Quran. As a natural consequence of such instructions, Muslims decisions 
are so influenced by their dependents, family members, friends, neighbors, local community, Muslim society, Humans, and even other creatures. Even though business transactions in Islam are also amenable to promote benevolent and lenient acts [22]. The Prophet Muhammad (PBUH) "May Allah's mercy be on him who is lenient in his buying, selling, and in demanding back his money" (alBukhari: Volume 3, Number 290) [23].

Clearly, now the Islamic philosophy shaped under the principle of cooperation instead of competition which activates the social harmonic interaction and Islamic brotherhood. See the verse number 10 of Surah Al-Hujurat where Allah says "he Believers are but a single Brotherhood: So make peace and reconciliation between your two (contending) brothers" [17]. Seemly, impossible to debate altruistic behaviours in Islam and that explains why egoism strictly criticized by Muslim scholars particularly the authors in [12] and [24] when they consider selfish assumptions as sufficient reason to reject the conventional utility model.

Criticizing the selfish assumption from Islamic point of view is not elusive, but proposing a confirmed Islamic alternative is thought to be a tedious mission. Meanwhile, alZarqa in [23] proposes to re-calls Al-Imam al-ghazali rule of social Interest i.e. al-Maslahah where decisions affect several levels of self, dependent, family, and broadly the whole society in which any decision taken must affect those levels partially. A more precise alternative has been suggested in [25] in which altruistic utility that compromising of self and others concerns utilized to interpret egoistic and altruistic behaves. By computing additive sum of those an individual feels altruistic towards, the altruistic utility behaves more disciplined compared to the conventional one in a manner closer to Islamic philosophy.

2) Utility Maximization: From secularly point of view and in harmony with egoism, human is full with desires and greed that heavily stimulated to be fulfilled in different ways. Satisfying those desires considered a primary human motive toward advancement in this life and a visible indicator for self-welfare [24]. Consequently, and in order to be in a better situation, each individual seeks to maximize his level of satisfaction by owning more payoffs in a form of money for instance or any other type. Decisions and choices, therefore, out to be in the same direction in which aims in the first place to maximize the level of satisfaction and hence maximizing self-utility. The utilitarian model, therefore, utilizes a positive increasing function to express that fact mathematically [1].

In a broad sense, there is a misconceived impression in which anticipated that conventional maximization assumption is Islamic harmonic believe because of Islamic authorization of acquisition behaves as have been briefly introduced in Section A.2. In fact, indiscriminate desires satisfaction is arguable from Islamic point of view because of the conflict with Islamic succession principle and the purpose of life [24]. Clearly, Islam believes in the hereafter as the real life compared to the temporary life i.e. this world's life. Individuals are required to behave in accordance with Allah orders in a disciplined manner where each activity considered religious duty i.e. Ibadah. Therefore, desires satisfaction is not the motive in Muslims situation but the success in the hereafter judgment. Accordingly, decisions in Islam supposed to be in convenience with religious provisions and if there is any conflict the priority must be to the more Islamic harmonic decision even at expense of self-desires. The Quranic verse 216 in Surat AlBaqarah reports this fact when Allah said "But it is possible that ye dislike a thing which is good for you, and that ye love a thing which is bad for you. But Allah knoweth and ye know not" [17]. In Al-Quran, self-desires expressed by the word "Shahwah" which mentioned three times all in nonpreferable situations see for instance the 14th verse of Surah al-Umran when Allah said "Fair in the eyes of men is the love of things they covet: Women and sons; Heaped-up hordes of gold and silver; horses branded (for blood and excellence); and (wealth of) cattle and well-tilled land. Such are the possessions of this world's life, but in nearness to Allah is the best of the goals (To return to)" [17]. Possibly because of this difference the studies in [20] and [24] introduced the weight of Iman i.e. God fearing to have important impact on Muslims utility. However, from technical perspective, it seems impossible to measure God fearing since it is a spiritual means and hence seems undesirable to include in Muslims utilities.

3) Utility Non-Satiation: Another objection seems relevant from Islamic point of view on the non-satiation utility property which assumes maximization continuity forever without limit. The justification behind that is the unlimited desire which incites for acquiring more without satiation. As a consequence, the phrase of "more always better than less" becomes far-famed in conventional utilitarian writings even though there exists some cases prefer less or equitable division. Non-satiation impacts utility by choosing increasing, monotonic and unlimited functions in which even a tiny increase is preferable even though the decision maker wealth sufficient.

Contrary, Islam urges for self-control and moderation in various aspects especially when interacting with other individuals as declared in the verse "Thus We have appointed you a middle nation, that ye may be witnesses against mankind" (Albaqarah:143) [17] . Accordingly, Islam criticized prodigal behaves and meanness as well. A natural impact for non-station assumption in consumption theory is prodigality where an individual decides to devote a large part of his wealth for luxuries while there are others in need for basics sufficiencies such as foods or clean water. Such behave receive an extreme argument in many Quranic verses in particular verse 31 of Surat Al-A'raf when Allah said "O children of Adam! Attend to your embellishments at every time of prayer, and eat and drink and be not extravagant; surely $\mathrm{He}$ does not love the extravagant" [17]. In the same manner, stinginess also criticized because of its impact to self-desires in which formerly reported that considered a religious duty in Islam. In line with that three Muslims scholar found declared their objection about non-satiation utility particularly Asad Zaman in [12], Bendjilali \& Bachir in [26], and Khan in [24] ). Instead, the study in suggests using two-level utilities where the second takes place after the first satiated. In contrast, prefer a limited utility function between upper and lower bounds in which utility never 
exceeds. In [24] another alternative introduced in which utility stops maximizing afterwards and its marginal rates equal zero at that state. In our perception, the first treatment is more applicable especially when we know that it comes in line with Islamic jurists prioritizing preferences.

4) Continuous Preferences: One of the significant stages in utilitarian development history is when (Von Neumann \& Morgenstern) successfully introducing utility axioms of completeness, transitivity, independence, and continuity [27]. Just to clarify each briefly, completeness assures that if there are any two alternatives then there must be a way to compare them either one is preferred or there is indifference relation. Transitivity preserves preference order on any set of alternatives. Interdependence proves that substitution between alternatives is preserved despite the nature of each. Continuity allows approximating preference relation of two alternatives in respect to their closer to other alternatives. Thus, continuing the process of approximation leads at the end to a place where decision maker indifference between alternatives [12]. However and in according to discussion, completeness, transitivity, and independence axioms seem convenient to Islamic provisions since there could not be found any conflict with Sharia norms but the only exception is the continuity axiom. The reason behind that is because continuity contradicts prioritizing the preferences in a discrete manner which seems more superb in accordance to Islamic jurists framework i.e. Asul Al-Figih where duties, desirable, neutral, less-desirable, and impermissible has to be clearly defined.

The natural contradiction for continuous preference is the discrete and prioritizing preference in which more than the level of satisfaction defined in advance. As discussed in [28], Imam Al-ghazali introduces the term Purposes of Shariah i.e. Maqasid Al-Shariah to define levels of satiation that each Shariah provision must fulfill before proceeding to the next. Accordingly, Yousof Al-Qardhawi stated his decision in [28] about preferring rescue poor and suffering people to performing Makah pilgrimage i.e. Haj. That is because of the view that Haj could be delayed to another opportunity while rescue and saving are urgent which indicates that choices, therefore, has different levels to be satisfied in a prioritized manner. In regard to consumption decision, [26] define a three consumption level namely: Tharurat, Hajiyyat, and Tahsinat in which Muslims aims at the beginning to fulfil basic needs for himself and other related socials, then looks broader for conventional satisfaction and lastly for accessories. For example, basic food and water are Tharurat, fruit is Hajiyyat, but luxuries are Tahsinat. However, although such view comes in line with Islamic norms but the mathematical interpretation seems quite difficult and requires a persuasive prove.

In a variant direction, Asad Zaman [12] and recently Hassilah Saleh [16] incorporating the principle of lexicographic preference in the Islamic consumption theory. In [12], a distinction takes place to the level of poor or sufficiency consumption and the level of luxuries. In order to resolve the arguments raised on the satiation and continuity properties discussed above, two conventional utility functions utilized in which one concerned with the basic needs satisfaction and the other with the luxuries. This is only a demonstration but more than two levels can be defined in a similar way. Therefore, a utility with three lexicographic levels can be defined as a proper treatment in which each corresponds to a specific level of consumption Tharurat, Hajiyyat, and Tahsinat as defined in [26]. Not so far, a similar approach used in to define a two dimensional utility that differentiate between worldly and Ukhrawi (spiritual satisfaction) commodities. The former is needed to achieve self-pleasure while the latter refer to spend of others. The worldly commodities defined in three levels as defined in [26]. While Ukhrawi commodities define another three levels correspond to Wajib (obligation), Mandoob (recommended), Mubaah (permissible). Then a utility function with three levels defined to determine the preference in between the bundle of commodities.

\section{RESULTS AND DISCUSSION}

So far, utilitarian decision making could not be considered fully compliant or fully contradicts Islamic provisions but partially suited and unsuited. Thus, a conclusion can be deduced in which there is a possibility to settle Sharia conflicts where a Sharia compliant decision making produced. In fact, the claim that certain method is Shariah harmonic is quite difficult challenge since a global consensus from Islamic organization required; nevertheless, the characteristics of Islamic model can be clearly identified from the aforementioned discussion. Before proceeding further, a look at the former discussion will be beneficial in order to summarize the landmarks as declared in Table 1. Islamic prospective seems to some extent accept the basic utility conception in which mathematically model human's attitude to some decisions. In the same direction confess the acquisitive nature of human instinct and appreciate that behavior under certain circumstances stated formerly. In the counterpart, utilitarian model compromised of four main deviations in which conflict to some Islamic provisions. Firstly, Islam urges for altruism while utilitarian struggle for egoism. Secondly, full desires satisfaction is arguable from Islamic point of view while the disciplined behaves more suburbs. Thirdly, non-satiation clashes with moderation and self-control and just principles. Lastly, continuous preferences insist for un-prioritization which contradicts jurist's framework i.e. Asul Al-Figih rules. Discrete preference allows more than the level of satisfaction is more superb.

Consequently, a number of treatments on the utilitarian decision model have to take place in order to be Islamic based and adhering Sharia principles. The first treatment is to replace the egoistic behaves with altruistic ones which capable of interpreting both behave correctly instead of considering the selfish one. Secondly, a precise definition of satiation levels in which individuals target to fulfil in a prioritizing manner. That leads to the last aspect which is introducing the lexicographic preferences. The following Table 1 summarizes the comparison between the utilitarian model and the Shariah requirements. 
TABLE I

The UTILITARIAN MODEL From ISLAMIC PERSPECTIVE

\begin{tabular}{|c|l|}
\hline \begin{tabular}{|} 
COMMON \\
DENOMINATORS
\end{tabular} & $\begin{array}{l}\text { 1. Utility Relation } \\
\text { 2. Acquisitive Nature }\end{array}$ \\
\hline & $\begin{array}{l}\text { 1. Egoistic Behaves } \\
\text { 2. Utility Maximization } \\
\text { 3. Utility Non-Satiation } \\
\text { 4. Continuous Preferences }\end{array}$ \\
\hline SETTLARITIES & $\begin{array}{l}\text { 1. Altruistic Utility } \\
\text { 2. Satiated Utility } \\
\text { 3. Lexicographic Preferences }\end{array}$ \\
\hline
\end{tabular}

In the following section, two important treatments ought to take place in order to harmonize the utilitarian model which includes the incorporation of Altruistic Utility and the Lexicographic preferences.

1) Altruistic Utility: Surprisingly, not only Muslims raises their objection on egoistic utility assumption but some western economic scholars attracted by the altruistic utility in particular [29], [30]. Through these studies, the assumption of selfish agent vanished and replaced by adopting beneficiaries' utility within self-utility. Accordingly, each altruist utility compromised of two parts: the self-utility which constructed from self-pleasure and the aggregate summation of others utility which represent the degree of altruism towards the beneficiary. The altruistic utility is interdependent utility in which concerns given to those related to the decision maker and an impact going to obtained to the taken decisions. Clearly, now altruistic utility capable of absorbing tender behaves and benevolent acts because the change on beneficiaries' utility going to influence the donor utility and that become harmonic to Islamic provisions. Evidently, the Prophetic saying i.e. Hadith narrated by Anas supported that when the Prophet Muhammed (PBUH) said: "None of you [truly] believes until he loves for his brother what he loves for himself" (AlBukhari: Volume 1, Number 13) [23].

However, the perfection of Muslim's acts might not be easily achieved because of the influence of the physical essence of the body which is not perfect compared to the spiritual side [31]. Therefore, the natural expectation is that Muslim might deviate from the true teachings of Islam and then even well literate Muslims might behave in an egoistic manner. Moreover, there might be situations where an individual behaves partially altruistic and partially selfish or behave altruistic towards some people and selfish towards others. Consequently, altruistic perception factor can be leveraged in which determines how much the decision maker feels altruistic towards each of the society members. Now, let defining the altruistic utility function of as follow:

Assume there is a society of $\mathrm{N}$ members in which each utility comprised of two parts including the utility derived from their self-pleasure and the other member's altruistic perception such that.

$$
U_{a l t}^{i}(x)=U_{s l f}^{i}(x)+\sum_{j \neq i}^{N} \mu_{i j} * U_{a l t}^{j}(x)
$$

\section{Where}

$U_{\text {sif }}^{i}(x) \quad$ : represents the self-utility consider it as any secular utility function

$U_{s i f}^{j}(x) \quad$ : represents the self-utility of the other members of the society

$\mu_{i j} \quad$ : represents the altruistic coefficient which can be deduced from the following matrix

$$
M=\left[\begin{array}{ccccc}
1 & \mu_{12} & \mu_{13} & \ldots & \mu_{1 n} \\
\mu_{21} & 1 & \mu_{23} & \ldots & \mu_{2 n} \\
\mu_{31} & \mu_{32} & 1 & \ldots & \mu_{3 n} \\
\vdots & \vdots & \vdots & \vdots & \vdots \\
\mu_{n 1} & \mu_{n 2} & a \mu_{n 3} & \cdots & 1
\end{array}\right]
$$

2) Lexicographic Preferences and Satiated Utility: As have been discussed earlier, preferences prioritization is more suburbs in Islam and accordingly there must be more than the level of prominence in which utility out to be maintained. To our perception, the treatment introduced by in which use the principle of satiated utility and lexicographic preference will contribute in settling objections of non-satiation and continuous preferences that rose against the conventional utility model. The term lexicographic utility has been introduced long time ago but never got attraction because of the dominant conventional utility conception. Fishburn in [32] has been attracted by the idea and extensively explore its axioms and properties. Instead of having a single continuous utility function, lexicographic preference maintaining different utilities in which lower level utilities must be satiated before proceeding to the next utility level. As a result, each used utility function shall comprise of satiation condition in which the utility could not exceed.

Mathematically, the general lexicographic ranking system can be seen as in the following equations:

$$
\begin{gathered}
\forall x, y \in A, \exists j, k \in \text { Integers and } j<k \\
x>y \Leftrightarrow U(x)>^{L} U(y) \Leftrightarrow
\end{gathered}
$$

\section{$\exists j, k \in$ Integers and $j<k$ such that}

$$
\text { if } U_{k}(x)>U_{k}(y) \Rightarrow \quad U_{i}(x)>U_{i}(y)
$$

Equation (3) can be rewritten in details such that:

$$
\begin{aligned}
& U(x)>^{L} U(y) \Leftrightarrow \\
& {\left[U_{1}(x)>U_{1}(y)\right]} \\
& {\left[U_{1}(x)=U_{1}(y), U_{2}(x)>U_{2}(y)\right]} \\
& {\left[U_{1}(x)=U_{1}(y), \stackrel{\text { or }}{\left.U_{2}(x)=U_{2}(y), U_{3}(x)>U_{3}(y)\right]}\right.} \\
& \text { [......] } \\
& {\left[U_{1}(x)=U_{1}(y), U_{2}(x)=U_{2}(y), \ldots, U_{n-1}(x)=U_{n-1}(y), U_{n}(x)>U_{n}(y)\right]}
\end{aligned}
$$


levels corresponded to Tharuryat (essentials), Hajyat (needs), and Tahsinat (accessories) where the highest priority to Tharuryat and then Hajyat and lastly Tahsinat. This means that alternatives belong to the lower levels must satisfy first before starting to the next level. This necessarily leads to define a satiated utility function which stops maximize it-self interminably.

Let us for this time denote the universal choice space with $\mathrm{Z}$ and define the following subsets.

$$
\begin{gathered}
Z=Z_{1} \cup Z_{2} \cup Z_{3} \text { such that } Z_{1} \cap Z_{2} \cap Z_{3}=\emptyset \\
Z_{1}=\{x: x \text { is any choice belongs to Tharuryat }\} \\
Z=\{x: x \text { is any choice belongs to Hajyat }\} \\
Z_{3}=\{x: x \text { is any choice belongs to Tahsinat }\}
\end{gathered}
$$

With help of equation (4) the following decision model can be defined:

$$
U(x)>\operatorname{L}(y) \Leftrightarrow\left\{\begin{array}{c}
U_{1}(x)>U_{1}(y) \\
\text { or } \\
U_{1}(x)=U_{1}(y) \text { and } U_{2}(x)>U_{2}(y) \\
\text { or } \\
U_{1}(x)=U_{1}(y) \text { and } U_{2}(x)=U_{2}(y) \text { and } U_{3}(x)>U_{3}(y)
\end{array}\right.
$$

Where:

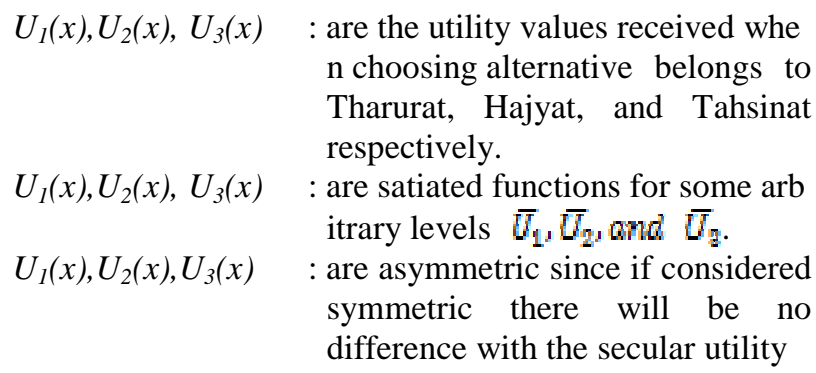

Lastly, it is important to emphasize that neither of the functions defined above $U_{1}(x), U_{2}(x)$, and $U_{3}(x)$ are individualistic but altruistic as defined in equation (2). However, the magnitude of the altruism coefficient $\mu_{i j}$ might not be the same on each of them since selfishness might be dominant in the case of necessity.

\section{CONCLUSIONS}

Through this paper, a brief comparison between conventional utilitarian and Islamic decision process has been introduced. Utility conception found relevant from Islamic point of view together with a confession that Islam urges for acquisitive behaves. Contrary, Islamic provisions raises objections against egoistic encouragement, nonsatiation, and un-prioritized preferences which are centric principles in the conventional utility model. By introducing the altruistic utility, satiated and lexicographic preferences the utilitarian model found that going to be more Islamic harmonic which paves the way for Islamic complaint decision making. In the future, it is hoped that the proposed treatments going to be implemented using computer simulation tools such as software agent in order to demonstrate Islamic legitimated decision models. Moreover, it is hoped that future researchers will be able to utilize the proposed treatments to construct a variety of automated intelligent systems that upholds the Islamic teachings and stimulates Islamic ethics. For Instance, the model can be applied to implement decisions support systems, enegotiators, automated trading agents like Shopbots or proxy bidders that stimulate for leniency and altruism.

\section{ACKNOWLEDGMENT}

The authors would like to thank Faculty of Information Science and Technology, Universiti Kebangsaan Malaysia by giving the authors an opportunity to conduct this research. This research is funded by Universiti Kebangsaan Malaysia under the Fundamental Research Grant Scheme FRGS/1/2014/ICT07/UKM03/2.

\section{REFERENCES}

[1] P. C. Fishburn, Utility Theory: Encyclopedia of Operations Research and Management Science, I. G. Saul and C. F. Michael, Eds, Boston: Springer, 2013.

[2] E. Kauder, History of Marginal Utility Theory, Princeton University Press, 2015

[3] J. L. Bermúdez, Decision Theory and Rationality, New York: Oxford University Press, 2011.

[4] J. Black, N. Hashimzade, G. Myles, and G. D. Myles, A Dictionary of Economic, 3rd ed., New York: Oxford University Press, 2012.

[5] H. Jazayeriy, M. Azmi-Murad, M. N. Sulaiman, and N. I. Udzir, "A review on soft computing techniques in automated negotiation," Scientific Research and Essays, vol. 6, pp. 5100-5106, Oct. 2011.

[6] D. J. Power, R. Sharda, and F. Burstein, Decision Support Systems, New Jersey, USA: John Wiley \& Sons, 2015.

[7] M. Cao, X. Luo, X. R. Luo, and X. Dai, "Automated negotiation for e-commerce decision making: a goal deliberated agent architecture for multi-strategy selection," Decision Support Systems, vol. 73, pp. 1-14, May. 2015.

[8] D. Sarne, "Competitive shopbots-mediated markets," ACM Transactions on Economics and Computation, vol. 1, p. 17, Jan. 2013.

[9] R. Carbonneau and R. Vahidov, "A multi-attribute bidding strategy for a single-attribute auction marketplace," Expert Systems with Applications, vol. 43, pp. 42-50, Jan. 2016.

[10] M. Al-Aaidroos, N. Jailani, and M. Mukhtar, "Automated web service SLA negotiation using multiagent system," in WIT Transactions on Information and Communication Technologies, 2014.

[11] A. Zaman and M. Karacuka, "The empirical evidence against neoclassical utility theory: a review of the literature," International Journal of Pluralism and Economics Education, vol. 3, pp. 366-414, Mar. 2012.

[12] A. Zaman, Microeconomics: An Islamic Perspective, S. Tahir, Ed. Kuala Lumpur: Longman, 1992.

[13] M. Al-Aaidroos, N. Jailani, and M. Mukhtar, "Lenient negotiation model based on altruistic utility and its implication on agentmediated negotiation," in Proc. ICEEI' 15, 2015, pp. 37-42.

[14] A. A. Adnan, "Islamic consumer behavior (ICB): its why and what," International Journal of Business and Social Science, vol. 2, Dec. 2011.

[15] M. N. Al-Attas, Islām and secularism, Kuala Lumpur, Malaysia: International Institute of Islamic Thoughts and Civilization, 1978.

[16] H. Salleh, R. Rasul, and S. M. Zain, "Two-dimensional model of lexicographic preferences," Applied Mathematical Sciences, vol. 7, pp. 5353-5362, 2013.

[17] A. A. Yusuf, The Holy Qur'an: Original Arabic Text with English Translation \& Commentary, Kuala Lumpur: Saba Islamic Media, 2000 .

[18] B. B. Bendjilali, F, "Towards a theory of Islamic consumer behavior," Journal of the Social Sciences, Kuwait University, 1989.

[19] A. Zaman, "Towards a new paradigm for economics," Journal of Islamic Economics, vol. 18, pp. 49-59, 2005.

[20] M. A. Al-Zarqa, "Islamic formulation of the social interest function and the theory of consumer behavior," Al-Muslim al-Muyasir, vol. 4, pp. 89-104, 1978. 
[21] M. T. Usmani, Ma'ariful-Quran, Karachi: Maktaba-e-Darul-Uloom, 1996.

[22] N. Jailani, M. Mukhtar, M. A. Al-aaidroos, A. Patel, S. Abdullah, Y. Yahya, Agent-Based Auction E-Marketplace with Value Added Services and Islamic Shariah Compliance: Encyclopedia of ECommerce Development, Implementation, and Management, IGI Global, 2016

[23] M. Al-Bukhari, Translation of the Meanings of Sahih Al-Bukhari: Arabic-English, Chicago: Kazi Publications, 1997.

[24] M. F. Khan, Essays in Islamic Economics, Toronto: Islamic Foundation, 1995.

[25] Q. Hamouri, Rationality, Time and Accounting for The Future in Islamic Thought. Essays in Islamic Economic Analysis, Genuine Publication \& Media PVT. Ltd., New Delhi, 1991.

[26] B. Bendjilali, "On muslim consumer behaviour: a mathematical setup," International Journal of Economics, Management and Accounting, vol. 3, Jan. 1993.

[27] J. Von Neumann and O. Morgenstern, Theory of Games and Economic Behavior, Princeton: Princeton University Press, 2007.

[28] Y. Al-Qardhawi, Priorities of the Islamic movement in the coming phase. al-Dār, 1994.

[29] J. Simon, "On the existence of altruistic value and utility functions," Theory and Decision, vol. 81, pp. 371-391, Mar. 2016.

[30] N. Frohlich, "Self-interest or altruism, what difference?," Journal of Conflict Resolution, vol. 18, pp. 55-73, 1974.

[31] M. K. Lodi, Islam and the West: The Clash Between Islamism and Secularism, Durham, UK: Strategic Book Publishing, 2011.

[32] P. C. Fishburn, Utility Theory for Decision Making, New Jersey: John Wiley \& Sons, 1970. 